\title{
Seasonal and interannual variations in pigments in the Adriatic Sea
}

\author{
Mira Morović \\ Institute of Oceanography and Fisheries, Šetalište I.Meštrovića 63, P.O.Box 500, 21000 Split, Croatia. \\ e-mail:morovic@izor.hr
}

\begin{abstract}
Spatial and temporal variability of pigments was studied from the CZCS satellite data and from in situ chlorophyll and transparency for the period 1979-1985. The three Adriatic sites, Northern, Middle, and Southern Adriatic are differently influenced by meteorological, hydrological and oceanographic parameters. The differences between seasonal in situ chlorophyll and remotely sensed pigment concentrations (from CZCS satellite data) from the Adriatic are large in winter. Through the correlation analysis, pigments were compared to meteo-oceanographic and hydrological parameters from different Adriatic sites. The PCA (principal component analysis) was applied to the pigment data series and significant components were compared. Different correlations are obtained for warm and cold periods of the year pointing to seasonal differences in the underlying mechanism of pigment variability. The first PC is influenced mainly by temperature. In the warm period more parameters seem to influence the pigment field, than in the cold period. The pigments in the Adriatic are in good correlation to a number of hydrologic and meteo-oceanographic factors.
\end{abstract}

\section{Introduction}

The Adriatic Sea in its shallow northern part receives considerable freshwater runoff, which significantly influences its productivity. Therefore, in this small marginal sea strong variations in thermohaline, color and nutrient gradients occur. The three sites, Northern, Middle, and Southern Adriatic have different climate properties, from the continental characteristics of the Northern Adriatic, deeply imbedded in European continent, to almost subtropical climate of the Southern Adriatic. Shallow Northern Adriatic (average depth $\sim 30 \mathrm{~m}$ ), depends on the freshwater inflow as well as the geomorphology of the bottom. The Middle Adriatic reaches $280 \mathrm{~m}$ in the Jabuka Pit, and is separated from the Southern Adriatic by the $170 \mathrm{~m}$ deep Palagruža Sill. The Southern Adriatic, with an average depth of $900 \mathrm{~m}$, reaches $1300 \mathrm{~m}$ in the Southern Pit. It is connected to the Mediterranean through the Otranto Strait, where interbasin water exchange takes place. Inten- sified advection of nutrient richer Mediterranean waters into the Adriatic is an important productivity factor for the oligotrophic Southern Adriatic and low productive Middle Adriatic (Marasovic et al 1995). The advection phenomenon is characterized with temperature and salinity which increases in the intermediate layer (Buljan and Zore-Armanda 1976). The LIW (Levantine intermediate water), has higher salinity (> 38.7 PSU) and higher temperature than the Adriatic waters (Zore-Armanda 1963). Periodical intensification of this inflow was related to climatic factors (ZoreArmanda 1963, 1969), since driving mechanism for enhancing interbasin exchange was explained via the pressure distribution over the larger area (ZoreArmanda 1969, 1972; Grbec and Morović 1997; Grbec et al 1998).

Oceanographic and meteorological elements are important for pigment dynamics in the Adriatic, some of them, like salinity, as an indicator of increased Mediterranean advection, while the others indicated changed climate conditions.

Keywords. Mediterranean; Adriatic Sea; CZCS; pigment concentrations; in situ chlorophyll; transparency. 


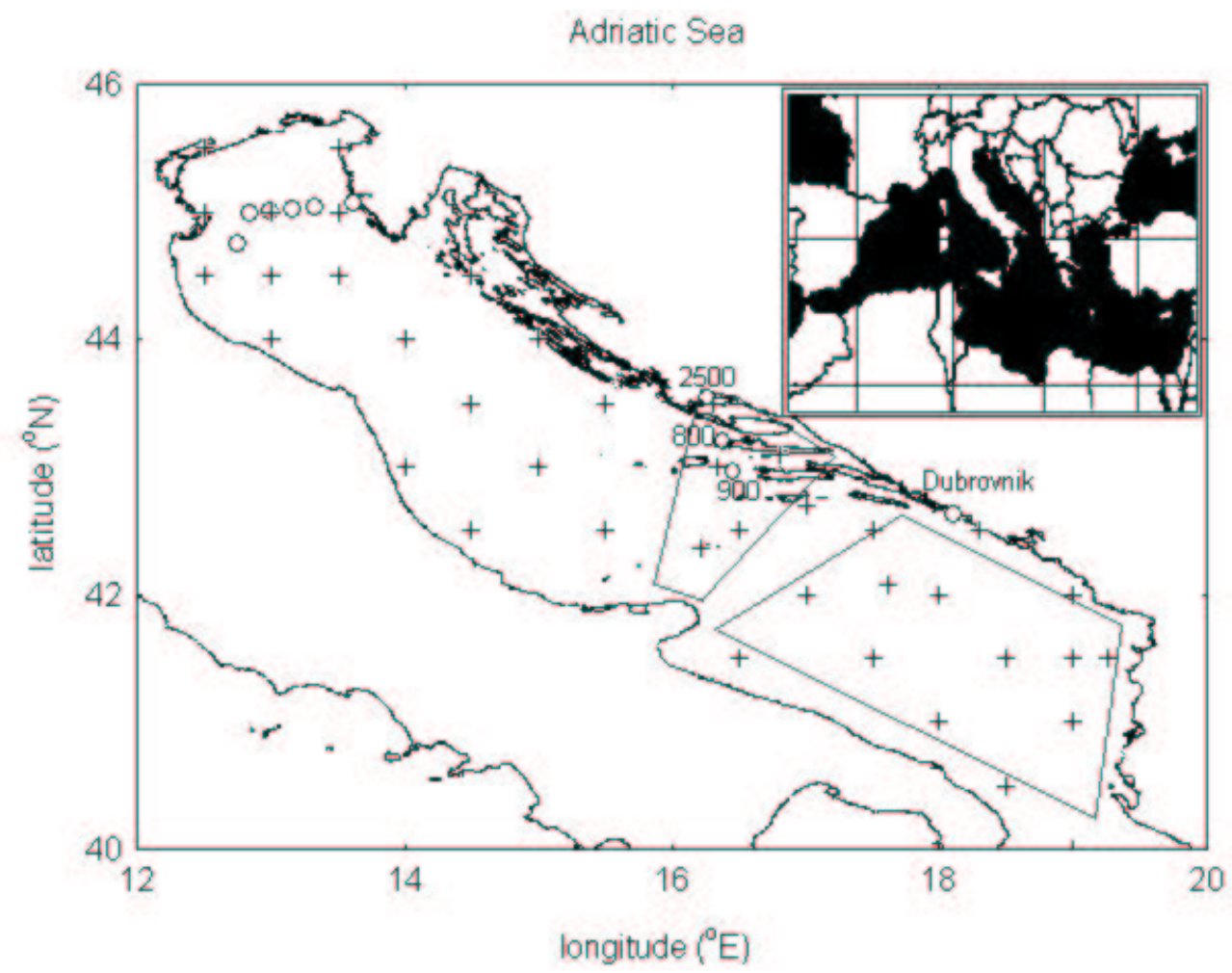

Figure 1. The Adriatic Sea (Northern Mediterranean) and location of satellite pigment data (cross marks) (from the OCEAN project database, via the http://www.me.sai.jrc.it site) and stations for in situ measurements of chlorophyll and transparency in the Adriatic (circles). Areas for in situ measurements of transparency in the Middle and Southern Adriatic are marked.

\section{Materials and methods}

Monthly mean CZCS pigment data averaged over $60 \times 60$ pixels from the Northern, Middle and Southern Adriatic, were obtained from the Stennis Space Center (La Violette 1996). Stations and areas of in situ and satellite data are given in figure 1. Monthly mean pigment data from 39 locations were retrieved from the database of the OCEAN project at the http://www.me.sai.jrc.it/ site. Monthly in situ chlorophyll pigments and transparency data for the Northern Adriatic were obtained from R. Precali from the Centre for marine research, Rudjer Boskovic Institute from Rovinj, Croatia. Oceanographic data from the Middle and Southern Adriatic were from the MEDAS (Marine Environmental Database of the Adriatic Sea) database of the Institute of Oceanography and Fisheries (Dadić 1996), and chlorophyll data were obtained from I. Marasović.

Gridpoint sea-level monthly pressure reconstructions were taken from the web site http://www.cru.uea.ac.uk/ (Trenberth and Paolino 1980; Jones et al 1987). Monthly mean meteorological data were obtained from the State Hydro-meteorological Institute of Croatia, and from the Bulletin of the Istituto Talassographico, Trieste.
One of the goals of this paper is to compare seasonal pigment concentration from the satellite to the in situ chlorophyll and transparency (Secchi disk) data. The time series of monthly mean pigment concentrations were analysed in relation to the temperature, wind speed, Po runoff, precipitation, global radiation and salinity, correlating the parameters and via correlations between PC scores from the pigment field. The warm and cold seasons were separated in correlation analysis, since they imply different vertical stratification and different spatial scales of influence.

\section{Results and discussion}

\subsection{Seasonal analysis}

Satellite derived pigment concentrations show similar seasonal variations in the whole Adriatic (figure 2) (Morović 1999). Maximum pigment concentrations were observed in autumn and in early winter. In February, pigment concentrations decrease in the whole Adriatic. In March, in the Northern Adriatic second annual maximum occurs, followed by lower pigment concentration in April and with a slight increase in May and June. Minimum pigment concentration is observed in August. 


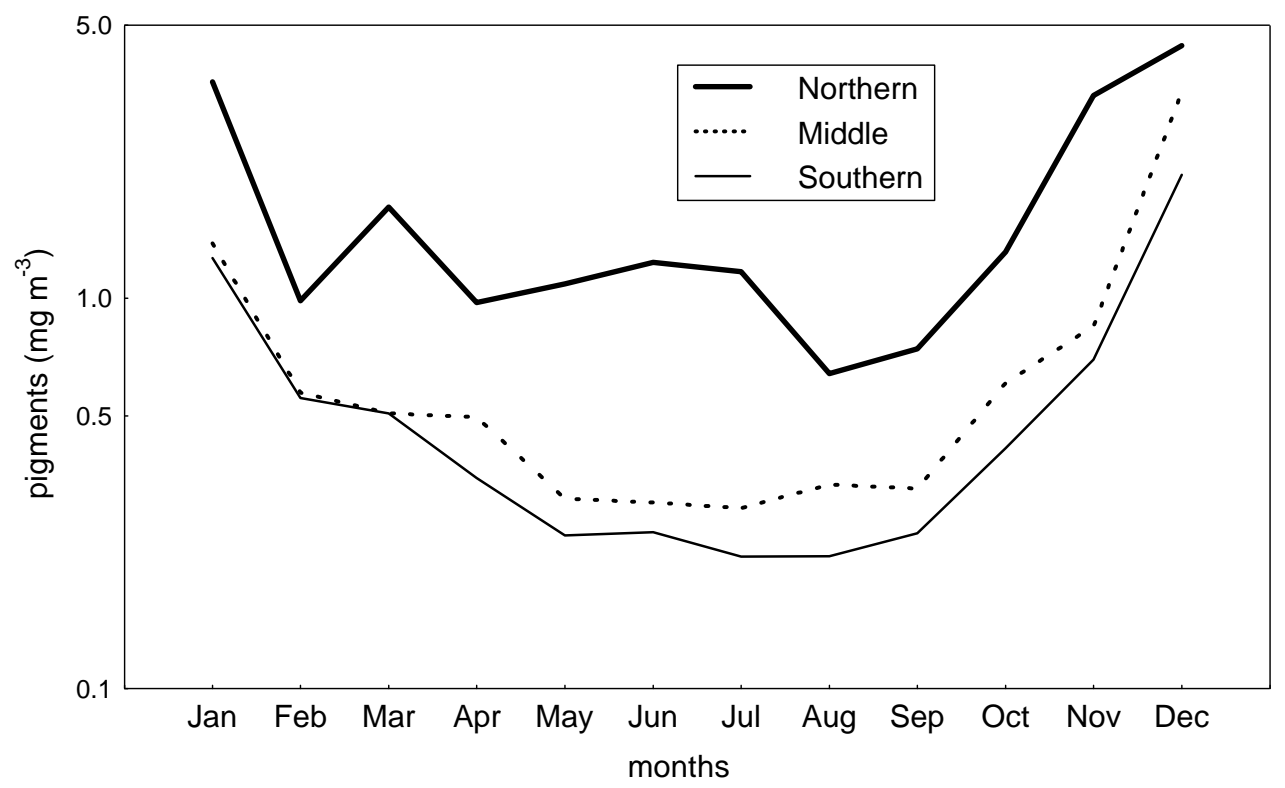

Figure 2. Seasonal course of monthly mean pigment concentrations for spatially averaged satellite data for the Northern, Middle and Southern Adriatic for the period 1979-1985 (La Violette 1996).

In September, concentrations are low, they increase in October and the increase continues in November. Annual pigment concentration maximum is in December, and almost the same concentration level is kept in January.

Annual course of the monthly concentration of in situ chlorophyll pigments (table 1) (Smodlaka 1985, 1986; Precali 1995) for the Northern Adriatic in winter months differs considerably from the pigments measured from the satellite. From the in situ data (figure 3), the three chlorophyll maxima can be seen (February, May and November), while the minimum, besides in summer months, occurs in January and December.

There is a correspondence in the minimum concentrations, in August, in both types of data. The most obvious difference between the two data is the winter maximum in satellite data in January and December, while in situ data in January and December had low concentrations. Comparing in situ chlorophyll to the monthly mean transparency (figure 4), the opposite course is observed most of the year. Especially August-September transparency maximum corresponds to the period of lowest chlorophyll concentrations. However, relatively low December and January transparencies correspond better to the pigments maximum from the satellite data series. Pigment concentrations measured from the satellite spatially averaged for the region of about $60 \times 60 \mathrm{~km}$, covered the stations of in situ measurements, and the spatial averaging should not be the reason for larger differences in some months. These differences show that in winter, there are other optically active substances in the water besides chlorophyll. In the Middle Adriatic also, the differences between the course of optically integrated in situ chlorophyll (Clark 1981) and pigment measured from the satellite were large in winter (figure 5). In the Middle Adriatic region, annual transparency course, with minimum in December or January (figure 6) is in accordance with the annual course of satellite pigment concentrations for this area (see figure 2). In the open Southern Adriatic region there were not enough chlorophyll data for seasonal analysis, while very sparse data were collected in the Dubrovnik region (figure 7). Annual transparency course for the Southern region (figure 8) with its minimum in December and January is in accordance with the annual course of satellite pigment concentrations for the region (see figure 2).

There may be a number of causes for the difference in pigments observed by the satellite and in situ chlorophyll. Bottom sediments, and/or DOM in the shallow Northern Adriatic may be present in the water column, due to the wind induced mixing, and could contribute to the color signal. Sediments and colored substances brought by rivers can also influence satellite color signal. Both may influence waters, not only in the shallow coastal regions, but waters could be advected to the other regions of the Adriatic. Precipitation brings nutrients and dissolved substances especially at the end of autumn, which can influence the water color. In addition to these, the sea becomes turbid after passages of cyclones; especially those that carried dust and/or sand from Spain or Africa (Genova cyclone). 
Table 1. Monthly mean in situ chlorophyll concentrations $\left(\mathrm{mg} \mathrm{m}^{-3}\right)$ (mean), number of data $(N)$ and standard deviations (stdev) for the period 1979-1985 for the stations of the Northern Adriatic transect from (see figure 1) for surface, 5 and 10 meters depth. These data obtained from R. Precali, were acquired from the Centre for Marine Research, Rudjer Boskovic Institute from Rovinj, Croatia.

\begin{tabular}{l|rrr|rrr|rrr}
\hline & \multicolumn{3}{|c|}{ Surface } & \multicolumn{3}{|c|}{$5 \mathrm{~m}$} & \multicolumn{3}{c}{$10 \mathrm{~m}$} \\
\hline Months & Mean & $\mathrm{N}$ & Stdev & Mean & $\mathrm{N}$ & Stdev & Mean & $\mathrm{N}$ & Stdev \\
\hline January & 0.91 & 6 & 0.28 & 0.90 & 6 & 0.25 & 0.86 & 6 & 0.32 \\
February & 3.64 & 14 & 4.09 & 5.03 & 9 & 1.73 & 2.34 & 14 & 1.83 \\
March & 2.79 & 36 & 3.58 & 2.22 & 26 & 1.94 & 1.48 & 36 & 1.75 \\
April & 2.20 & 21 & 4.84 & 0.59 & 6 & 0.12 & 0.49 & 21 & 0.21 \\
May & 3.18 & 32 & 5.66 & 2.00 & 28 & 2.15 & 0.73 & 32 & 0.50 \\
June & 2.36 & 19 & 3.66 & 1.09 & 19 & 0.65 & 0.75 & 19 & 0.37 \\
July & 0.93 & 78 & 0.89 & 0.79 & 75 & 0.59 & 0.71 & 74 & 0.58 \\
August & 0.90 & 38 & 1.19 & 0.45 & 34 & 0.36 & 0.43 & 34 & 0.29 \\
September & 0.62 & 15 & 0.70 & 0.42 & 15 & 0.21 & 0.48 & 15 & 0.29 \\
October & 2.30 & 23 & 2.20 & 1.33 & 19 & 0.81 & 1.30 & 19 & 0.60 \\
November & 3.17 & 19 & 2.43 & 3.16 & 18 & 1.93 & 1.97 & 19 & 1.18 \\
December & 1.20 & 29 & 1.11 & 1.15 & 25 & 0.74 & 0.81 & 29 & 0.37 \\
\hline
\end{tabular}

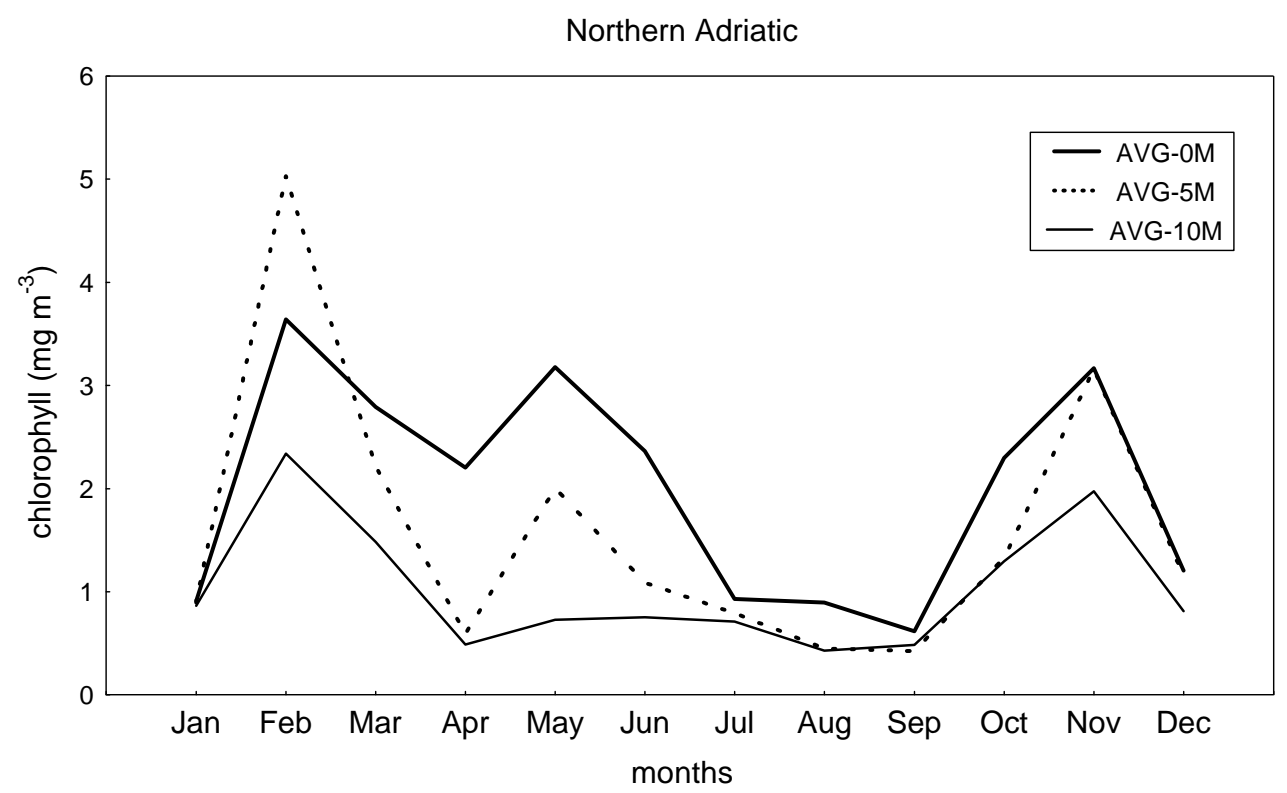

Figure 3. Monthly mean in situ chlorophyll pigments for stations from the Northern Adriatic for the surface, 5 and $10 \mathrm{~m}$ for the period 1979-1985. (Data according to R. Precali, pers. comm. Centre for Marine Research, Rudjer Boskovic Institute from Rovinj, Croatia.).

\subsection{Interannual analysis}

Correlation coefficients were calculated between the pigment concentrations from averaged areas, and hydro-meteorological monthly mean data (table 2). For the whole year, Northern Adriatic pigment concentrations are in significant negative correlations with the air and sea temperature and global radiation, which are due to the opposite annual course. Positive correlation coefficients are found between pigments and wind speed and precipitation. Although the Po River runoff plays an important role in the dynamics of the Northern Adriatic pigments, inflows and pigments were not significantly correlated at the scale of monthly means. For the warm season, pigments from the Northern Adriatic were in good correlation to the pressure difference between Trieste and Dubrovnik 


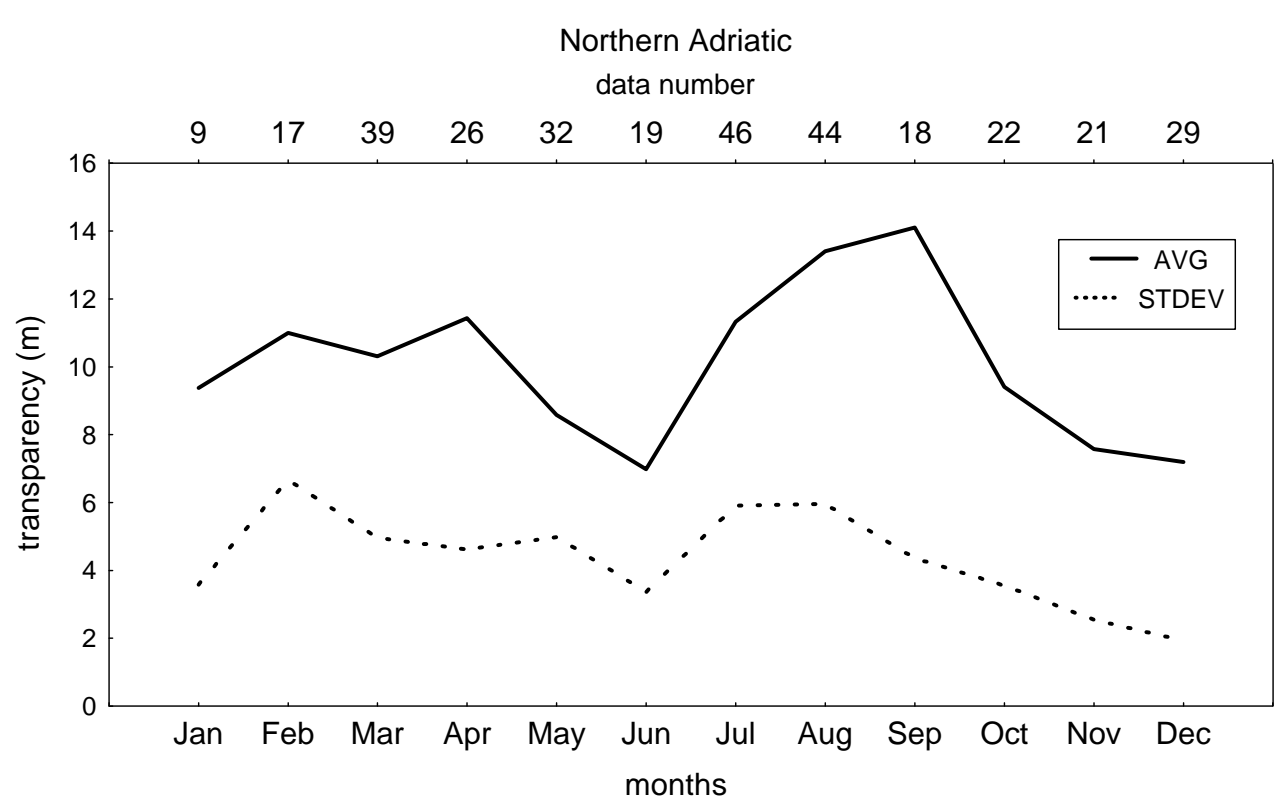

Figure 4. Monthly mean transparency and standard deviation for stations from the Northern Adriatic for the period 1979-1985. (Data according to R. Precali, pers. comm. Centre for Marine Research, Rudjer Boskovic Institute from Rovinj, Croatia). Number of data per month is indicated at the upper axis.

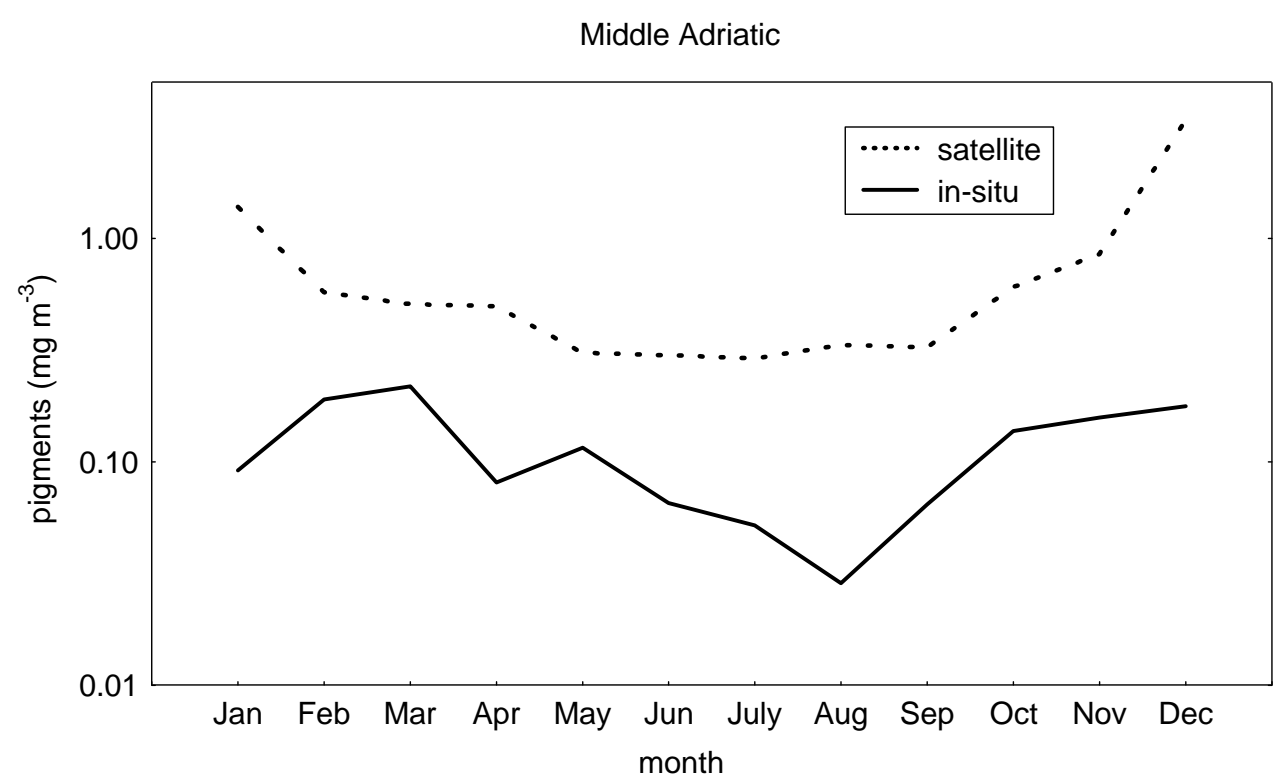

Figure 5. Seasonal course of pigment concentrations according to spatially averaged satellite data for the Middle Adriatic (La Violette 1996) and in situ chlorophyll pigments $\left(\mathrm{mg} \mathrm{m}^{-3}\right.$ ) (optically integrated within the penetration depth) for Stončica station in the Middle Adriatic (in situ chlorophyll data were obtained from I. Marasović, pers. comm. Institute of Oceanography and Fisheries, Split).

and sea temperature from the Middle Adriatic station. Both indicate the advection of less productive Middle Adriatic water. In the cold season only significant correlation between pigments and global radiation exist.

Pigments in the Middle Adriatic for the whole season are in significant correlation with temperature, precipitation and the wind speed. However, separately warm and cold seasons are best correlated with salinity parameters. Negative correla- tion of salinity to pigments in the warm period is influenced by the riverine waters. Nutrients which lead to the higher chlorophyll production can be advected in the surface layer, together with dissolved colored substances, carried by the runoff, where both can increase pigment concentrations. This can explain relatively higher pigment in August in the Middle Adriatic. The influence of the Northern Italian waters especially the Po river has been detected in the Middle Adriatic during 


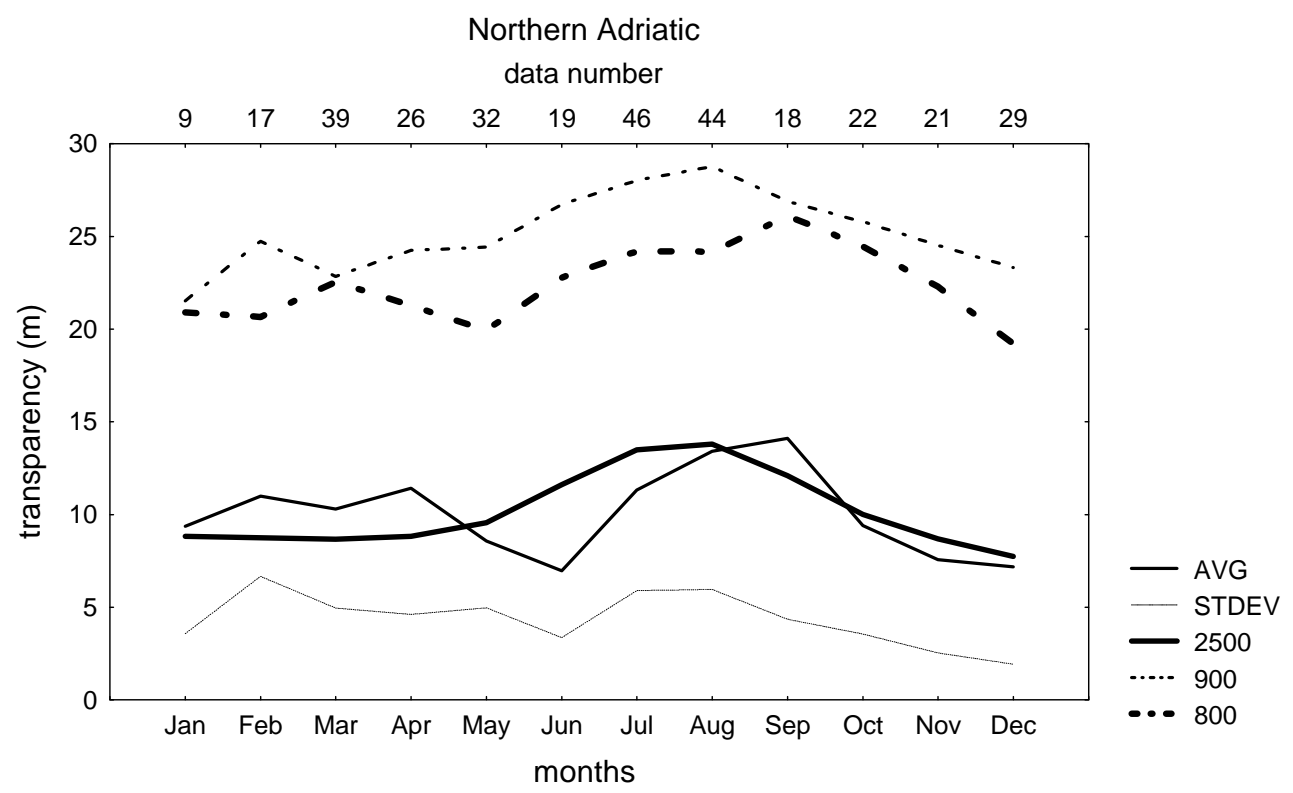

Figure 6. Monthly mean and standard deviation of transparency $(\mathrm{m})$ averaged for the Middle Adriatic area for the period 1979-1985 and monthly means for stations Stončica-900, Pelegrin-800 and Kaštela Bay-2500 in the period 1952-1983, according to the MEDAS database. Number of data per month is indicated at the upper axis.

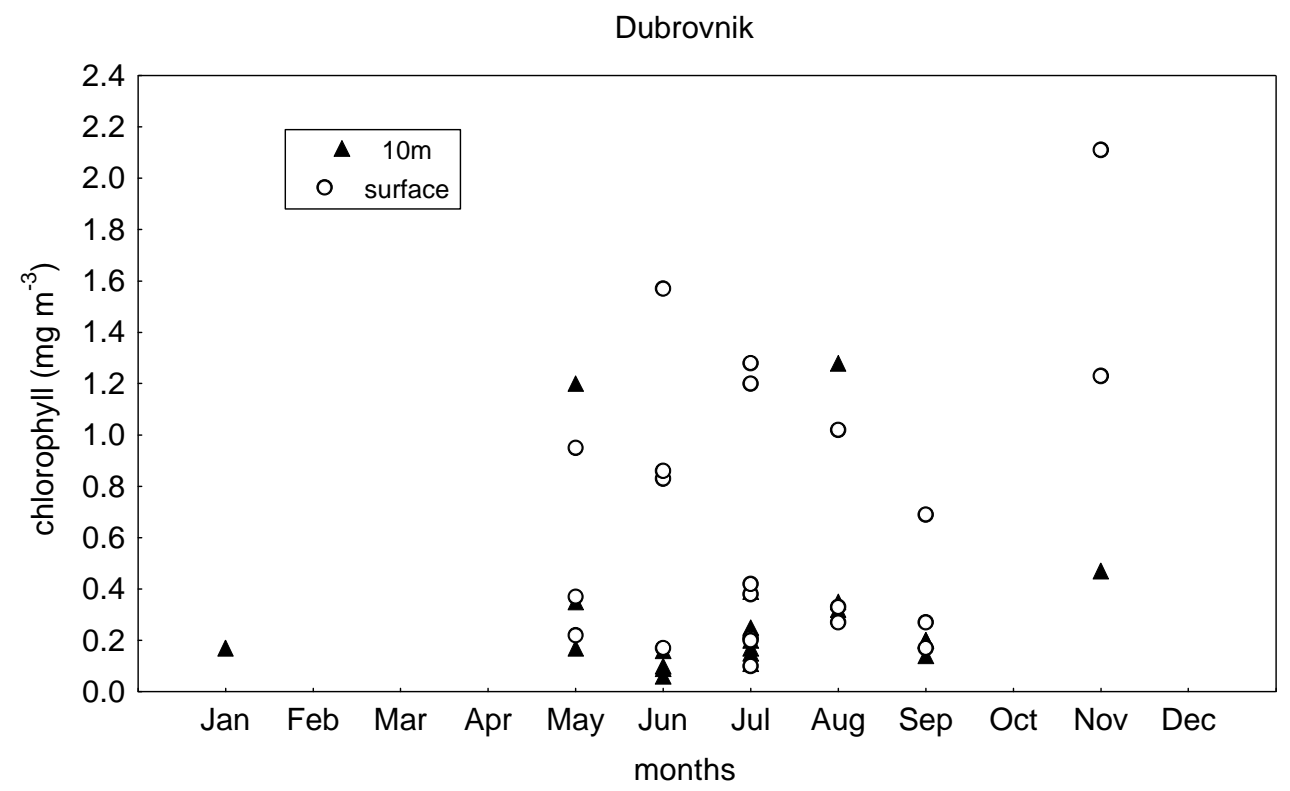

Figure 7. In situ chlorophyll pigments for the region near Dubrovnik in the Southern Adriatic, for surface layer and $10 \mathrm{~m}$, for the period 1979-1985. (Data according to I.Marasović, pers. comm. Institute of Oceanography and Fisheries, Split, from individual measurements).

the warm period. It is because in the stratification period, lighter river water from the Italian rivers spreads at the surface and reaches the Middle Adriatic, causing spring salinity minimum at the Split-Gargano transect (Grbec and Morović 1997). The low salinity water was also found in the surface layer of the Jabuka Pit in the Middle Adriatic (Pucher-Petković and Zore-Armanda 1973). Positive correlation between pigments and salinity in the cold period may have the reason in the advection of nutrient richer LIW (Marasović et al 1995).

The pigments of the Southern Adriatic are in positive correlation to the wind and precipitation for the whole year, while negative correlations exist with temperature and salinity in the warm season. This negative correlation of salinity to pigments in the warm period is influenced by the fresh water input from the Albanian rivers. 


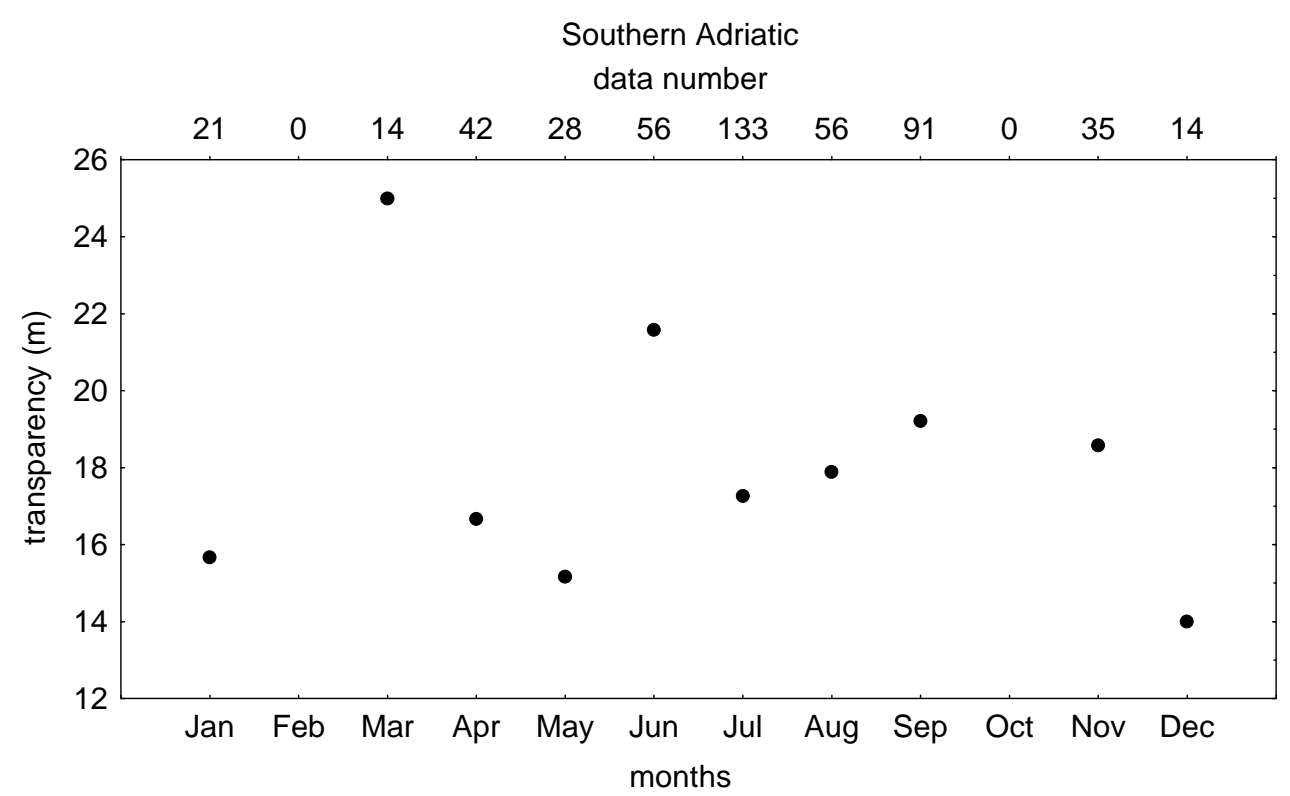

Figure 8. Monthly mean transparency $(\mathrm{m})$ in the Southern Adriatic region in the period 1979-1985, according to the MEDAS database. Number of data per month is indicated at the upper axis.

Table 2. Correlation coefficients between monthly mean pigment concentrations (CZCS data) from spatially averaged areas, log (pigment concentrations) and meteo-oceanographic parameters (A) for the whole measuring period; (B) for the warm period April-September and (C) for the cold period October-March. Stations for the measured parameters are indicated; $\Delta$ Salinity is salinity anomaly; correlation coefficients were significant at $p<0.01$.

\begin{tabular}{|c|c|c|c|c|c|c|c|}
\hline Station & Parameters & \multicolumn{3}{|c|}{ Pigments } & \multicolumn{3}{|c|}{ Log pigments } \\
\hline \multicolumn{2}{|l|}{ (A) } & North & Middle & South & North & Middle & South \\
\hline & Air temperature & & & & -0.44 & & \\
\hline & Sea temperature & & & & -0.63 & & \\
\hline & Global radiation & & & & -0.56 & & \\
\hline & Temperature & & -0.53 & & & -0.60 & \\
\hline & Precipitation & & 0.31 & & & & 0.40 \\
\hline & Wind & & & & & 0.43 & 0.48 \\
\hline
\end{tabular}

(B)

\begin{tabular}{l|l|lll|ll}
\hline & Sea temperature & -0.52 & & & & \\
& Salinity & & -0.42 & -0.53 & & \\
& $\Delta$ Salinity & & -0.34 & -0.49 & -0.34 & -0.46 \\
Dubrovnik & Air temperature & & & -0.49 & & \\
Trieste- & Pressure & -0.43 & & & & \\
Dubrovnik & difference & & & & & \\
\hline
\end{tabular}

(C)

\begin{tabular}{l|l|l|ll}
\hline Trieste & Global radiation & & -0.46 & \\
Stončica & Salinity & & & 0.40 \\
\hline
\end{tabular}

\subsection{Fluctuation analysis}

Increased salinity and production, and reduced transparency in the Southern and Middle Adriatic are the consequences and the indicators of LIW advection into the Adriatic (Zore-Armanda 1972; Buljan and Zore-Armanda 1976; Grbec et al 1998). Therefore, salinity at the Stončica station showed 


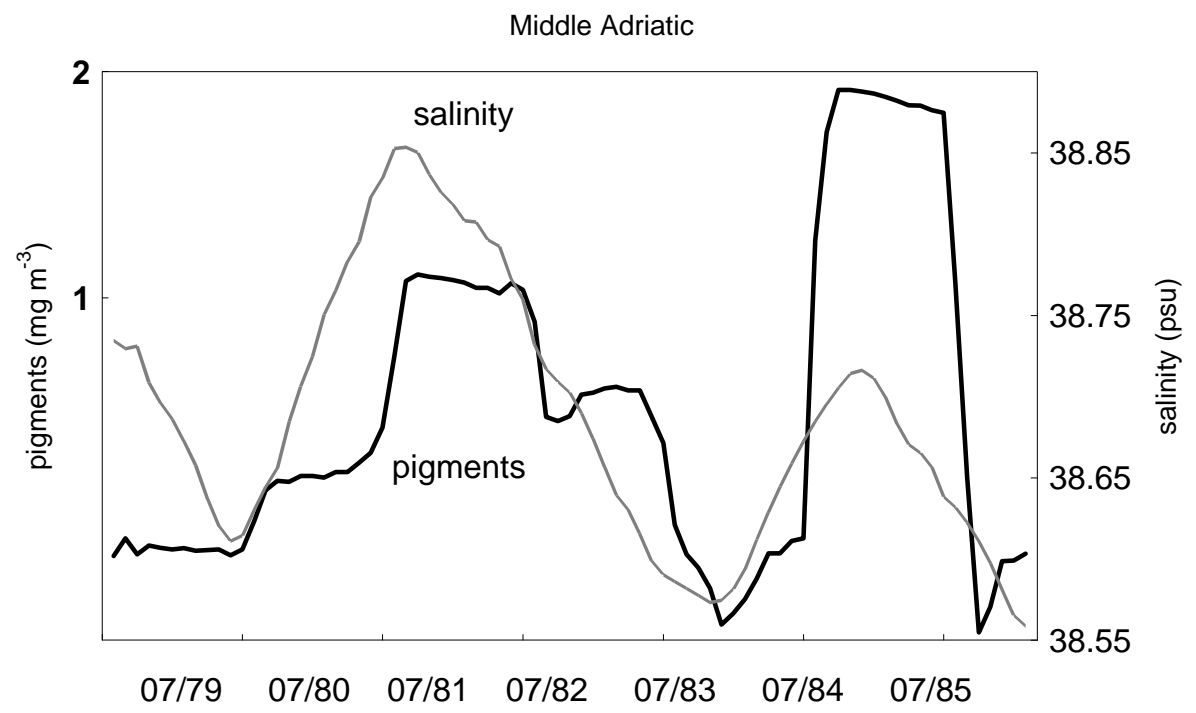

Figure 9. Mean monthly pigment concentrations $\left(\mathrm{mg} \mathrm{m}^{-3}\right)$, for the Middle Adriatic, and monthly mean salinity (psu) at Stončica station, filtered with 12 -term moving average.

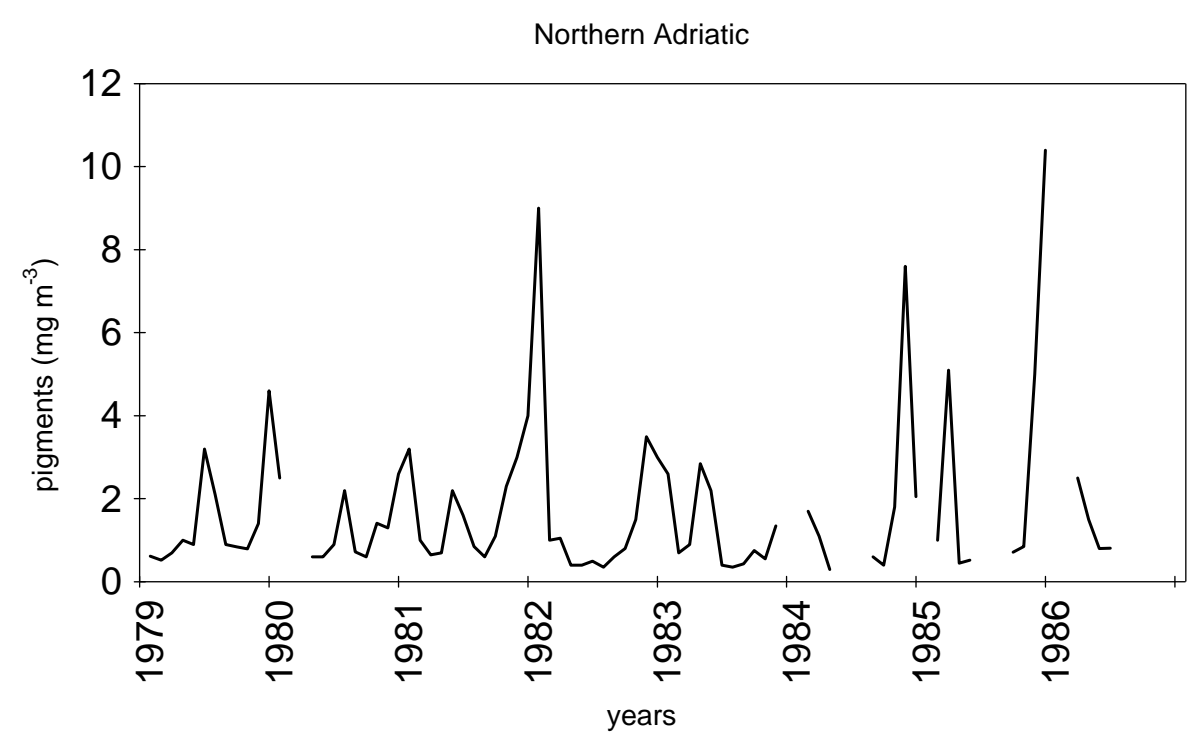

Figure 10. The time series of mean monthly pigment concentrations $\left(\mathrm{mg} \mathrm{m}^{-3}\right)$ for the Northern Adriatic.

correspondence of the maximum periods with the highest pigment concentrations in the Middle and Southern Adriatic, when filtered at the annual scale (figure 9).

In spite of the lack of strong correlation between some hydro-meteorological elements and pigment concentrations it may be possible that highest pigments were the consequences of extreme meteorological events. Therefore, the time-series of pigments (figure 10) for the Northern Adriatic were compared to the wind speed episodes above $8 \mathrm{~m} / \mathrm{s}$ and Po runoff above $2500 \mathrm{~m}^{3} \mathrm{~s}^{-1}$ (figure 11). It is possible to distinguish that extreme pigment events occurred when they coincided with extremes of wind and/or runoff.

\subsection{PC analysis}

In order to better understand the dynamics of pigments the PC analysis was done for the timeseries of pigment concentrations from 39 stations (see figure 1), in order to find characteristic features of the pigment fluctuations. PCA was performed on a correlation matrix of standardized variables (Preisendorfer 1982). Eigenvalues (PCs) and eigenvectors were determined applying the varimax normalized rotation. Seven significant components (PC1 ‥PPC7), explaining almost $80 \%$ of the total variability of the pigment field were found. The first carried $50 \%$ of the total field variability, and is proportional to the mean pigment 


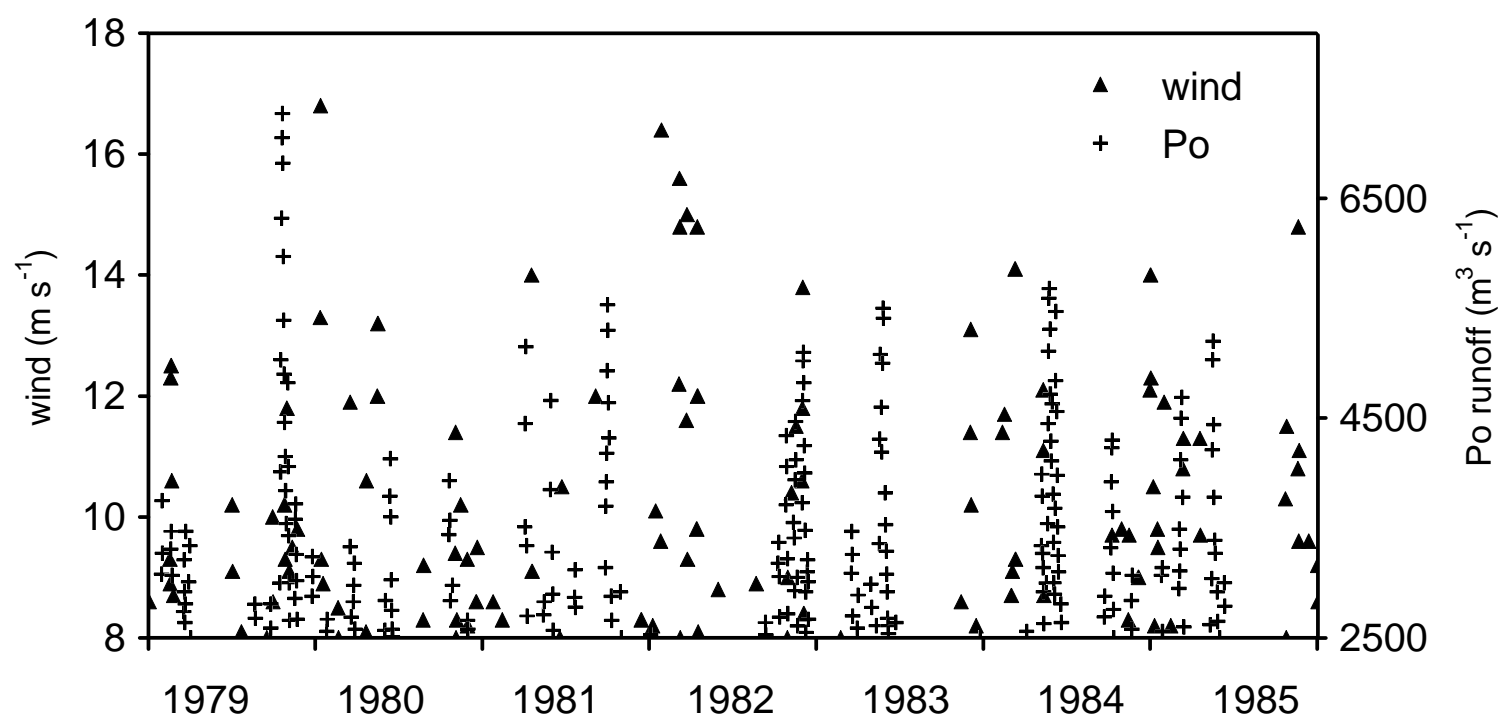

Figure 11. Daily mean wind speed for Trieste $\left(\mathrm{m} \mathrm{s}^{-1}\right)$ (higher than $8 \mathrm{~m} \mathrm{~s}^{-1}$ ) and the Po River daily runoff (higher than $\left.2500 \mathrm{~m}^{3} \mathrm{~s}^{-1}\right)$.

Table 3. Correlation coefficients between principal component scores of the pigment field and meteo-oceanographic parameters (A) for the warm period April-September and (B) for the cold period October-March. Stations for the measured parameters are indicated; grid points coordinates (for the pressure differences) are as follows: $46(50 \mathrm{~N}, 0 \mathrm{E}), 75(35 \mathrm{~N}, 10 \mathrm{~W})$ and $79(35 \mathrm{~N}, 30 \mathrm{E})$. Correlation coefficients were significant at $p<0.05$.

\begin{tabular}{|c|c|c|c|c|c|c|c|c|}
\hline Stations & Parameters & & & Princ & pal com & onents & & \\
\hline (A) & & $\mathrm{PC} 1$ & $\mathrm{PC} 2$ & PC3 & $\mathrm{PC} 4$ & $\mathrm{PC} 5$ & PC6 & $\mathrm{PC} 7$ \\
\hline & Air temperature & -0.32 & 0.37 & & -0.55 & & -0.41 & -0.42 \\
\hline & Sea temperature & & & & -0.51 & & & -0.41 \\
\hline & Global radiation & & & & & -0.41 & & \\
\hline & Wind speed & & & & & & 0.42 & \\
\hline & Precipitation & & -0.37 & & 0.38 & & & 0.38 \\
\hline Pontelagoscuro & Po runoff & & & & 0.46 & & & \\
\hline & Air temperature & -0.31 & 0.34 & & -0.57 & & -0.35 & -0.4 \\
\hline & Wind speed & & & -0.31 & & & & \\
\hline & Precipitation & & -0.54 & -0.39 & 0.31 & & 0.61 & 0.44 \\
\hline Stončica & Salinity & -0.39 & & 0.36 & & -0.41 & & \\
\hline Grid points $46-79$ & Pressure difference & & 0.47 & 0.35 & -0.66 & -0.31 & -0.39 & -0.38 \\
\hline Trieste-Dubrovnik & Pressure difference & & 0.35 & 0.35 & -0.42 & & & \\
\hline (B) & & F1 & $\mathrm{F} 2$ & F3 & $\mathrm{F} 4$ & F5 & F6 & F7 \\
\hline & Precipitation & & & & 0.35 & -0.36 & & \\
\hline & Air temperature & -0.31 & & & 0.34 & & & \\
\hline & Wind speed & & & & -0.37 & & & \\
\hline Pontelagoscuro & Po runoff & & & 0.39 & & & & \\
\hline Dubrovnik & Air temperature & & & & 0.33 & & & \\
\hline & Wind & & & 0.37 & & & & \\
\hline Stončica & Salinity & & & & 0.49 & & & \\
\hline Grid points $75-79$ & Pressure difference & & & & & 0.31 & & \\
\hline Trieste-Dubrovnik & Pressure difference & & & & -0.54 & 0.35 & & \\
\hline
\end{tabular}


field in the Adriatic. The component scores were correlated to the meteo-oceanographic parameters (table 3).

One of the correlated elements here is the pressure difference at the monthly scale. Link between zonal pressure difference and salinity (and temperature) is well known in the Middle and Southern Adriatic (Zore-Armanda 1969, 1972; Grbec et al 1998), since it provides the mechanism for advection of the LIW into the Adriatic. It was found that the pressure differences were strongly related to the advection of Mediterranean waters into the Adriatic (Grbec et al 2002), although these analyses were done at the annual scale. The pressure differences influence changes of most hydro-meteorological factors at the monthly and even lower scales. From the earlier work (Grbec et al, submitted), when annual pressure values were used, significant correlation was found for the pressure difference between Mid-North Atlantic and South-East Mediterranean and the salinity in the Middle Adriatic. Here, pressure differences from various gridpoints were combined to obtain best correlation coefficients with pigments in the Adriatic. For the warm season highest correlation coefficients with pressure differences are obtained for different grid points over the Northern Atlantic, which points to the difference in seasonal distribution of major pressure systems. In the warm period, correlation between the PC4 to pressure difference G46-79 is highest $(-0.66)$. In the cold period, significant correlation of $\mathrm{PC} 4$ remains with the pressure difference between Trieste and Dubrovnik $(-0.54)$. The PC4 has high correlation to salinity for the cold period (0.49). In the warm period PC5, PC1 and PC3 were in good correlation to salinity.

The first principal component in both seasons have influence only from temperature. In the warm period there were more significant correlation coefficients which could have influenced the pigment field, than in the cold period. It seems that PC4 component is the one that explains part of the pigment field variability which is in good correlation to the meteorological parameters in the cold period, while in the warm period other PCs also depend on meteorological factors. It can be seen that the pigment field responded to the Po river inflow with different modes of variability for the warm and cold periods. The highest correlation coefficient with Po runoff is found with PC4 for the warm period (0.46). The PCs of the pigment field have significant correlation to the sea temperature and global radiation in the warm period. The response of the pigment field to the precipitation and wind is different, depending on the season.

\section{Concluding remarks}

Seasonal values of the pigment concentrations obtained from CZCS showed winter pigment maximum in December and January, while in situ measured chlorophyll, did not show high values in that period. However, winter pigments maximum is in accordance with the seasonal transparency course in most of the Adriatic regions, indicating the possibility that other optically active substances are present in the sea in that period.

The whole Adriatic has coherent seasonal pigment dynamics, and its changes are correlated to a number of hydrologic and meteo-oceanographic factors, whose fluctuation periods correspond to the fluctuation periods of pigments. The pigments dynamics especially in the Northern Adriatic, are influenced by the strongest wind and runoff episodes which may cause mixing of shallow bottom sediments and introduce optically active substances in the water column.

Some of the principal component scores of the pigment field are in significant correlation to hydrometeorological elements, but with different PCs for warm and cold period, pointing that different factors are governing pigment dynamics in different seasons.

Significant correlation between the PCs of the pigment field, to the pressure differences shows that variability of the pressure field over the wider area, plays an important role in the spatial and temporal dynamics of pigments. This could be achieved via the direct influence of pressure differences on meteorological elements (especially to the wind), or regulating the exchange of water with the surrounding Mediterranean. Significant correlation coefficients between PC4 and the Po River runoff shows that runoff plays an important role in the variability of the pigment field in the Adriatic. The PC1 in both seasons are influenced by the temperature. In the warm period more factors influence the pigment field.

\section{References}

Buljan M and Zore-Armanda M 1976 Oceanographical properties of the Adriatic Sea; Oceanogr. Mar. Biol. Ann. Rev. 14 11-98

Clark D K 1981 Phytoplankton pigment algorithms for the Nimbus-7 CZCS In: Oceanography from space, (ed.) J F R Gower (New York: Plenum Press) pp: 227-238

Dadić V 1996 MEDAS, Mediterranean Environmental Database of the Adriatic Sea, Proceedings. Elmar 38th International Symposium Electronics in Marine. 2426.06.1996: 60-65

Grbec B and Morović M 1997 Seasonal thermohaline fluctuations in the middle Adriatic Sea; Nuovo Cimento della Societa Italiana di Fisica C-Geophysics 85 Space Physics 20(4) 561-576 
Grbec B Morović M and Zore-Armanda M 1998 Some new observations on the long-term salinity changes in the Adriatic Sea; Acta Adriat. 39(1) 3-12

Grbec B, Dulčić J, Morović M 2002 Long-term changes in landings of small pelagic fish in the eastern Adriaticpossible influence of climate oscillations over the Northern Hemisphere; Climate Research 20 241-252

Grbec B, Morović M and Zore-Armanda M Mediterranean oscillation and water masses distribution in the Adriatic Sea (submitted to Continental Shelf Research)

Jones P D, Wigley T M L and Briffa K R 1987 Monthly mean pressure reconstructions for Europe (1780-1980) and North America (1858-1980). DOE Technical Report No. Tr037. U.S. Department of Energy, Carbon Dioxide Research Division, Washington, D.C.

La Violette P 1996 Monitoring of the coastal and marine environment with satellite data; Sistema Terra. pp: 56-61

Marasović I, Grbec B and M Morović 1995 Long-term production changes in the Adriatic; Neth. Journ. of Sea Res. 34(4) 267-273

Morović M 1999 Spatial and temporal changes of optical properties of the Adriatic Sea retrieved from remote sensing of pigment concentrations. (Croatian) Ph.D. Thesis, University of Zagreb pp 1-178

Preisendorfer R W 1982 Principal Component Analysis in Meteorology and Oceanography (Amsterdam: Elsevier), pp: $1-425$
Precali R 1995 The analysis of inter-annual cycles of primary production in the Northern Adriatic and process of eutrophication. (Croatian) Ph.D Thesis. University of Zagreb, pp 1-146

Pucher-Petković T and Zore-Armanda M 1973 Essai d'evaluation et prognostique de la production en function des facteurs du mileu dans l'Adriatique; Acta Adriat. 15 $1-39$.

Smodlaka N 1985 Primarna proizvodnja organske tvari kao indikator eutrofikacije u sjevernom Jadranu. Dissertation. University of Zagreb, pp. 1-262

Smodlaka N 1986 Primary production of organic matter as an indicator of eutrophication in the Northern Adriatic Sea; Science of Total Environment, 56 $211-220$

Trenberth K A and Paolino D A 1980 The Northern hemisphere sea-level pressure data set: Trends, errors, and discontinuities; Month. W. Rev. 108 855-872

Zore-Armanda M 1963 Les masses d'eau de la mer Adriatique; Acta Adriat. 10 1-94

Zore-Armanda M 1969 Watter exchange between the Adriatic and the Eastern Mediterranean; Deep-Sea Res. 16 $171-178$

Zore-Armanda M 1972 Response of the Mediterranean to the oceanographic/meteorological conditions of the Northern Atlantic; Rapp. Comm. int. Mer Médit. 21 203205 